\title{
Scope of mobile health in Indian health care system - the way forward
}

\author{
Farhad Ahamed ${ }^{1}$, Sarika Palepu ${ }^{2 *}$, Mahasweta Dubey ${ }^{1}$, Baridalyne Nongkynrih ${ }^{1}$
}

\author{
${ }^{1}$ Centre for Community Medicine, All India Institute of Medical Sciences, New Delhi, India \\ ${ }^{2}$ Department of Community Medicine and Family Medicine, All India Institute of Medical Sciences, Bhubaneswar, \\ India
}

Received: 03 February 2017

Accepted: 06 March 2017

\section{*Correspondence:}

Dr. Sarika Palepu,

E-mail: sarikapalepu@gmail.com

Copyright: (c) the author(s), publisher and licensee Medip Academy. This is an open-access article distributed under the terms of the Creative Commons Attribution Non-Commercial License, which permits unrestricted non-commercial use, distribution, and reproduction in any medium, provided the original work is properly cited.

\begin{abstract}
India is currently undergoing increased urbanisation and population growth. The existing health care facilities and health care personnel are not able to cater to the health care needs of the population. Hence, a demand-supply gap is prevailing in the country. Improper functioning of three tier health care delivery, inaccessibility of secondary and tertiary government health services are the other major hurdles in effective health care utilisation. Technological interventions like tele-consultation strived continuously to tackle this crisis but had attained limited success. Other technological advancements as mobile based interventions (mHealth) have been emerging in the recent times. mHealth includes the use of telecommunication and multimedia technologies integrated with mobile and wireless healthcare delivery system. With success stories round the globe, it can be marked that mobile technology in the present scenario has gained substantial effects on health outcomes. Using mobile technology offers a tremendous opportunity for developing countries as India to advance in health care delivery by effectively utilising scarce resources. The vastly underserved healthcare market combined with high mobile phone penetration and rapidly growing smart phone adoption creates enabling environment condition for mHealth adoption in India. mHealth, being user friendly and cost effective, would be an interesting initiative in developing world. Customised application and sustainable financial models which could suit the existing local healthcare delivery networks would yield beneficial outcomes.
\end{abstract}

Keywords: Mobile health, mHealth, Health care system, Tele-communication, India

\section{INTRODUCTION}

India is the second largest populated country in the world with two thirds living in rural areas. Demographic and environmental transition in the country is augmenting the already existing high burden of communicable, noncommunicable and emerging infectious diseases. ${ }^{1}$ Through years, India has made a large stride in improving overall health scenario. Impediments as large geographical size, high population density, lack of good quality transport facilities, inadequate nutrition, illiteracy and poverty have hindered in achieving good quality health care. Statistics suggest differences in urban-rural health condition in terms of infant mortality rate and crude death rate, a harsh reality even today. ${ }^{2}$ Significant disease burden, limited human resources, high absenteeism of health care providers at government facilities, inaccessibility to quality health care by rural dwellers augments the existing hardships in health care delivery in the country. ${ }^{3-5}$

Challenges do exist in health care delivery due to nonexistent three tier referral system, and inaccessibility of secondary/tertiary government health services. ${ }^{6}$ Existing challenges in health care delivery necessitates an urgent need of enabling three tier referral systems with information communication technology applications. ${ }^{7}$ It has been envisaged to use telemedicine in providing 
healthcare services and enabling health care providers working at primary level. But, implementation of telemedicine is still limited to few private and prestigious tertiary care public hospitals. Moreover, the cost of teleconsultation is too high to introduce in remote healthcare settings. ${ }^{8}$

In view of unsuccessful implementation of Telemedicine technology, a low cost technologic alternative is the need of the hour. The application of mobile technology in the health sector has the complete potential to change the face of global health systems. ${ }^{9}$ In developing countries mobile devices have reached more people than electricity, road systems and clean piped water. A rapid technical development in mobile technology, falling market prices of the product, increasing network coverage and an explosive increase of cell phone user rates are the positive driving factors enabling the rising opportunity in terms of healthcare delivery. ${ }^{10}$ The far-flung spread of mobile technologies and advancements to address health priorities has evolved into a new field of eHealth known as mHealth (mobile health).

mHealth offers the potential for enhanced reach by providing individually tailored and customized services, even among traditionally underserved populations, at relatively low cost. ${ }^{11,12}$

The aim of this article is to discuss about the globally successful mHealth interventions and the scope of mHealth in Indian context along with challenges to address. This article strives to provide an insight into the possible alternate cost-effective interventions in Indian context and the need for further research in the field of mHealth.

\section{METHODOLOGY}

The aim of this review article is to focus on the scope of mhealth interventions globally and in India. Literature search was done in Pubmed, Google scholar etc with the key words mobile health, mHealth, health care system, India. Articles related to successful mhealth interventions globally for the year 2015-16 were retrieved and included in this study. For a better comprehension of mhealth in the recent times and its effect in India, only recent global interventions were taken into account. To explain the existing mhealth scenario in India, search was extended to the past decade (2006-2016). Interventions which already existed in India and recently launched interventions are discussed henceforth. An effort was made to bring forth the possible challenges in implementing this technology. The article also discusses about the probable way forward in successfully implementing this innovative technology to address the demand supply gap in health care provision.

\section{WHAT IS mHEALTH?}

mHealth includes the use of telecommunication and multimedia technologies integrated with mobile and wireless healthcare delivery system. The WHO's Global Observatory for eHealth defined mHealth as "medical and public health practice supported by mobile devices, such as mobile phones, patient monitoring devices, personal digital assistants, and other wireless devices"." mHealth is in its early stages of development. However, it has already started to transform healthcare delivery due to success of mHealth applications and programs that have been implemented in the developing world. Mobile devices which can be used in mHealth include laptops, tablets, mobile phones, smart phones, palmtops, notebook and netbook.

\section{DOMAINS OF MHEALTH INTERVENTIONS}

The mHealth services presently existing vary in their level of sophistication from static information provision to comprehensive health care management.

It had gained far-ranging service spectrum as empowering elderly and expectant mothers, chronic disease management as reminding people of medication timings, extending service to underserved areas and improving health outcomes and medical system efficiency. $^{13}$

Interventions such as tele-consultation, video consultation over 3G, appointment scheduling, triaging and SMS prescription services are among the widely prevalent spectra of healthcare service provision. ${ }^{14}$

Other common application domains for mHealth are client education and behaviour change, registries and vital events tracking, data collection and reporting, electronic health record, electronic decision support: information, protocols, algorithms, checklists, providerprovider communication: user groups consultation, patient-provider communication, provider work planning and scheduling, provider training and education, sensors and point of care diagnostics, human resource management, supply chain management, financial transaction and incentives. ${ }^{14-19}$

Partnerships between healthcare and telecom providers have made the substitution of traditional care and expansion of existing accessibility of health care feasible. ${ }^{17}$ The goals of implementing various mHealth applications are to enhance the efficiency and the accessibility of healthcare systems and to reduce the mortality in developing countries. ${ }^{20}$

\section{WORLDWIDE MHEALTH SCENARIO}

A 2011 global survey of 114 nations by WHO found that mHealth initiatives have been established in many countries but there is variation in adoption levels. Africa 
had the lowest rate of mHealth adoption while North America, South America and Southeast Asia showed highest adoption level. ${ }^{21}$

A study by United Nations Foundation and Vodafone Foundation has listed 51 mHealth programs that are operating in 26 developing countries all over the world. These programs and projects focus on six main areas: treatment and support service, data collection and remote monitoring services, disease surveillance and drug adherence services, health information systems and point of care services, and emergency medical services. ${ }^{20,22}$

The most frequently reported types of mHealth initiatives globally were health call centres/ health care telephone help lines $(59 \%)$, emergency toll-free telephone services $(55 \%)$, emergencies $(54 \%)$, and mobile telemedicine (49\%). The least frequently reported initiatives were health surveys (26\%), surveillance (26\%), awareness rising $(23 \%)$, and decision support systems $(19 \%) .^{21}$

\section{FEW GLOBAL mHEALTH INITIATIVES}

For an insight into the implementation of mHealth interventions worldwide, few success stories have been discussed below. With further research, these interventions can be tailored for utilisation in Indian settings.

- Sustainable successful scaled up mHealth applications such as Gluco Phones have been implemented in the United States (monitor and transmit blood glucose levels), Text4Baby(how to handle various stages of pregnancy and problems that arise) and Heal the Trax (virtual health assistant). ${ }^{23}$

- Indonesia, has two applications which are citizens interfacing known as Dokita (our doctor) and DokterGratis (free doctor). Dokita and DokterGratis allow patients to chat and consult with physicians. Another mHealth application has been in use in rural province of Indonesia where mobile phones are used by midwives to transmit health statistics, contact peers for advice, to communicate with doctors and to receive health updates. ${ }^{23}$

- The mRamadan initiative, started in Senegal is based on mobile technology to improve access to support for people with diabetes. The aim of the programme was to send SMS tips and advice to enrolled diabetics during Ramadan to promote good health behaviours during and between fasting periods and had drastically reduced emergencies arising in Ramadan period. ${ }^{24}$ India, being home to 69.2 million diabetics, $(8.7 \%$ of adult population), has adopted mDiabetes since the year $2016 .^{25}$

- mTikka, is an application used by vaccine workers in Bangladesh for infant registration. This application was used to automatically generate customized vaccination schedules and reminders were sent to parents. This application enabled enhanced accessibility of infants' vaccination status through database all over the country. ${ }^{26}$ There are currently 5 billion mobile phone subscriptions in the world according to the International Telecommunication Union. Over $85 \%$ of the world's population is now covered by a commercial wireless signal and hence judicial investment in the field of mHealth would reach far-off areas. ${ }^{27}$ Though more than three decades have passed since the inception of Universal immunisation programme, immunisation coverage with DPT-3 in Indian children still stands at $75 \%$. Alternate mechanisms through increased awareness and timely reminders as in mTikka interventions could enhance the coverage of immunisation in the nation.

\section{mHEALTH AND ITS SCOPE IN INDIA}

As per Telecom Regulatory Authority of India press release, on $30^{\text {th }}$ November, 2015, there are almost 1009 million (577.84 million urban and 431.61 million rural) telephone subscribers. ${ }^{28}$ India is the second-largest mobile phone user country with over 900 million users in the world. It accounted for over $10 \%$ of the world's online population in 2011. The high penetration of mobile technology in India, therefore offers a positive promising scope for mhealth utilisation in health care provision.

The advancements in technology and communications in health care scenario are also evident in India. An effort to discuss few existing mHealth interventions in India is made henceforth.

1. Maternal \& child health: Most mHealth projects in India started their journey in 2008. Maternal and child tracking system was first of its kind where messages are sent to Janani Suraksha Yojana (Mother security scheme) beneficiaries and accredited social health activist workers. This innovation helped in improving service delivery, and meeting the service needs of health care providers. ${ }^{29}$

2. NIKSHAY: The government of India had introduced a mobile-based intervention called NIKSHAY in 2012. It is a web enabled application, which facilitates monitoring of universal access to Tuberculosis (TB) patient's data by all concerned personnel. The innovative information technology (IT) application of NIKSHAY makes it possible for the grass-root level healthcare providers to track every TB patient. ${ }^{30}$

3. Awareness generation is another prevalent mHealth domain in the country. National Organ Transplant Organization is spreading awareness regarding organ donation among general population via SMS services.

4. Government of India has launched various mhealth initiatives nationwide on $15^{\text {th }}$ January 2016 as a part of Digital India program. The intent of the program was to enhance access, make healthcare services cost effective and to make the system more robust. ${ }^{31}$ 
These initiatives were Kilkari, Mobile academy, MCessation and TB missed call initiative.

a. Kilkari: delivers free weekly, time appropriate 72 audio messages about pregnancy, child birth and child care directly to families' mobile phones starting from the second trimester of pregnancy until the child is one-year old.

b. Mobile academy: is a free audio training course designed to expand and refresh the knowledge base of accredited social health activists and improve their communication skills. Training opportunity is provided via their mobile phones which is both cost effective and efficient.

c. M-Cessation: It aims at reaching out to those willing to quit tobacco use and support them towards successful quitting through text messages sent via mobile phones. This stands superior to traditional methods of cessation interventions.

d. TB missed call initiative: a helpline with a toll free number which will provide information, counseling and treatment support services for TB patients.

\section{CHALLENGES IN IMPLEMENTING mHEALTH IN INDIA}

Main limitation of mHealth service is lack of two-way interaction between service provider and the consumer limiting their credibility and sense of personalized care. ${ }^{17}$ Though there were 97,000 mHealth apps in 2013 in major app stores ${ }^{32}$, majority of them are based on a commercial spectra with focus on health care lagging behind. ${ }^{33,34}$ Increased self-care and self-monitoring by mHealth innovations, though beneficial might invite risk as judicial interventions by healthcare professionals is inevitable in some instances. ${ }^{35,36}$ The growing number of self-testing devices are also a concern regarding ethical, psychological and social aspects of individuals.

Rural India face the biggest shortage of health manpower. mHealth, though has the potential to supply cost-effective care to rural India has many challenges. ${ }^{36}$ Some of the issues that may hinder successful implementation of mHealth technology include poor phone access in rural households (58\%), lack of reliable power supply to charge phones, poor smart phone user rates, and low literacy rates.

Sustainable scaling up of successful mHealth interventions demands necessary knowledge and undivided attention from policy-makers. Relentless investment by administrators poses major hurdles in further advancements in this field. The other challenges for ground implementation of mHealth are developing an adequately strong infrastructure, education and training targeting towards new technology in orthodox professionals and healthcare personnel, lack of adequate research and development into major thrust areas of healthcare where mHealth would be worthiest.
Enhanced use of mHealth interventions also raise concern over individual privacy and data security. ${ }^{38}$ As many of the mHealth apps handle a lot of sensitive and private information appropriate secure handling to protect privacy is mandatory.

Though revolutionary technological advancements are made in the area of mHealth, demand driven and need based investment are the impending factors for further progress in this field.

\section{WAY FORWARD}

mHealth has a great potential to deliver life-saving information even in the most remote and resource constraint settings in developing countries and can serve as an access point of national surveillance systems. ${ }^{39}$ Cost-effective monitoring through mHealth interventions could pave a way for increased quality and accessibility to a wider array of health care services.

Well-being of the individual and community is a prerequisite for economic and social development. Using mobile technology to improve health offers a tremendous opportunity for developing countries and communities to advance in health care delivery and effectively utilise scarce resources by making health systems more efficient. mHealth provides immense opportunity to mitigate the problem of health care personnel absenteeism and become alternative of telemedicine.

Mobile technology in the present scenario has gained substantial effects on health outcomes in some areas and, if there is a provision of scope to excel in supportive regulatory environments with strategic interventions by policymakers and funders, a lot more can be availed in the coming years.

The propensity to pay for health care in poorer countries is higher as the cost of care exceeds the income earned by the individuals. The vastly underserved healthcare market combined with high mobile phone penetration and rapidly growing smart phone adoption creates enabling environment condition for mHealth adoption in India. Individually tailored messages would have a high acceptance by the community as their health needs would be met. mHealth, being user friendly and cost effective, would be an interesting initiative in developing world. Customised application and sustainable financial models which could suit the existing local healthcare delivery networks would yield beneficial outcomes. ${ }^{36}$

Interventions as telephone based appointment scheduling, SMS prescription refill services, consultation via $3 \mathrm{G}$ video or telephone provides quality care just a smart phone away. ${ }^{38}$ mHealth interventions would effectively tackle the rising burden of chronic diseases as demonstrated by few studies. Increased compliance can be ensured through reminders over mobile phone and hence can increase the quality of life of chronic disease 
sufferers. $^{40}$ Communicating results of medical investigations via mHealth technology would save much time for the patients. ${ }^{41}$

Mobile phone text messaging for promoting adherence to antiretroviral therapy in patients with HIV infection has been found effective. ${ }^{42}$ Similarly, adherence to iron folic acid supplementation therapy can be improved by using mHealth technology. Mobile phone based interventions for improving contraceptive use is another area where we could explore the effectiveness of mHealth. ${ }^{43}$

Mobile phones, computers and tablets can enhance healthcare delivery and lower operating costs in India. mHealth is reducing readmission rates in chronic patients through better monitoring and higher compliance rates for prescribed care. Regular check-ups can be easily industrialized through remote monitoring using mobile, interpreted by data analytics at the health clinics. mHealth in India could be used to substitute a portion of future physical infrastructure of hospitals and clinics through remote diagnosis, monitoring and care. Healthcare practitioners need to be encouraged, trained and ultimately mandated to adopt mHealth as a part of their methods for diagnosis, and staying connected with the patients.

Strongest indicators of awareness and use of mHealth services is monthly spending on mobile phone services. However, individuals with lower mobile spending believe that mHealth services are easier to use than the current healthcare services. Therefore, mHealth has the potential to fill the gaps in the system by providing expanded access at lower cost. ${ }^{36}$ India is still far away from achieving universal immunization. ${ }^{44}$ Short Message Service (SMS) texts using existing MCTS services may offer a potential low-cost solution in India and may leverage India's drive to vaccinate all children against vaccine preventable disease. ${ }^{45}$ Rational investment in enhancing immunisation coverage through mHealth can also yield prudent results.

Use of tobacco is an important concern from public health perspective. Evidence of text message based smoking cessation has been found effective among young population. ${ }^{46}$ It is another important area where mHealth might be a fruitful intervention to spread awareness regarding harmful effects on health by tobacco use and gain from cessation of tobacco use.

Reducing high burden of malnutrition is another area of concern in India. Increasing burden of obesity is adding to the already prevailing burden of under-nutrition. ${ }^{47,48}$

Through mHealth, citizens become more empowered and informed of their health and wellbeing. Communication ties and health knowledge between patients and healthcare providers and even amongst healthcare providers would be enhanced greatly.
Rational adoption of mHealth interventions prevalent globally following mERA checklist, tailored to the existing needs in the country can be a prudent investment to effectively combat the burden of health care delivery. ${ }^{49}$

\section{CONCLUSION}

India is currently facing shortage of health manpower. There are fewer instances of using technology in public healthcare delivery. Vast coverage of mobile services in India and success of mHealth worldwide opens a new window in healthcare delivery in India. Hon'ble prime minister has also envisaged for a digital India where mHealth might be the most promising domain to explore in health sector. Further research into the existing mhealth interventions and their scope in Indian context needs a focus. It will be a prudent decision to invest in further research in mHealth which has all potentiality to be a cost-effective alternative of long reared dream to introduce information communication technology in public health.

The current study envisages the scope of mhealth in India. However, accessibility, utilisation, effectiveness of mhealth interventions in Indian context needs to be focused in greater detail. There is a need for further systematic reviews to evaluate the existing interventions with special focus on their scope in developing nations such as India.

\section{Funding: No funding sources Conflict of interest: None declared \\ Ethical approval: Not required}

\section{REFERENCES}

1. Chauhan L. Public health in India: issues and challenges. Indian J Public Health. 2011;55(2):88.

2. Registrar General of India. Sample Registration System Bulletin 2014;49:1-6. Available at http://censusindia.gov.in/vital_statistics/SRS_Bullet ins/SRS\%20Bulletin\%20-Sepetember\%202014.pdf. Accessed 10 Nov 2016.

3. Lakshminarayanan S. Role of government in public health: Current scenario in India and future scope. J Fam Community Med .2011;18:26-30.

4. Chaudhury N, Hammer J, Kremer M, Muralidharan $\mathrm{K}$, Rogers FH. Missing in action:teacher and health worker absence in developing countries. J Econ Perspect. 2006;20(1):91-116.

5. Yadav K, Jarhyan P, Gupta V, Pandav CS. Revitalizing Rural Health Care Delivery: Can Rural Health Practitioners be the Answer? Indian J Community Med. 2009;34:3-5.

6. National Urban Health Mission. Framework for Implementation. May 2013. Ministry of Health and Family Welfare. http://nrhm.gov.in/images/ pdf/NUHM/Implementation_Framework_NUHM.p df. Available at http://nrhm.gov.in/nhm/nuhm/ 
nuhm-framework-for-implementation.html.

Accessed 16 Nov 2016.

7. Car J, Sheikh A. Telephone consultations. BMJ. 2003;326:966-9.

8. Praveen KB, Ali SS. Telemedicine in Primary Health Care: The Road Ahead. Int J Prev Med. 2013;4:377-8.

9. mHealth. New horizons for health through mobile technologies. Global observatory for eHealth seriesvolume 3. World Health Organization. Geneva. Switzerland. Available at http://www.who.int/goe/ publications/goe_mhealth_web.pdf. Accessed 18 Nov 2016.

10. Piette JD, Lun KC, Moura LA, Fraser HSF, Mechael PN, Powell J, et al. Impacts of e-health on the outcomes of care in low- and middle-income countries: where do we go from here? Bull World Health Organ. 2012;90:365-72.

11. Chang BL, Bakken S, Brown SS, Houston TK, Kreps GL, Kukafka R, et al. Bridging the digital divide: reaching vulnerable populations. J Am Med Inform Assoc. 2004;11:448-57.

12. Walji M, Sagaram S, Sagaram D, Meric-Bernstam F, Johnson C, Mirza NQ, et al. Efficacy of quality criteria to identify potentially harmful information: a cross-sectional survey of complementary and alternative medicine web sites. J Med Internet Res. 2004;29(6):e21.

13. Anzaldo-Campos MC, Contreras S, Vargas-Ojeda A, Menchaca-Díaz R, Fortmann A, Philis-Tsimikas A et al. A Randomized Control Trial Evaluating the Impact of Project Dulce and Short-Term Mobile Technology on Glycemic Control in a Family Medicine Clinic in Northern Mexico. Diabetes Technol Ther. 2016;18:240-51.

14. Labrique AB, Vasudevan L, Kochi E, Fabricant R, Mehl G. mHealth innovations as health system strengthening tools: 12 common applications and a visual framework. Glob Health Sci Pract. 2013;1:160-71.

15. Dulce Wireless Tijuana: Empowering Communities to Promote Diabetes Care and Prevention Through 3G Technologies. Qualcomm wireles reach. Mexico. Available at: https://www.qualcomm.com/ wireless-reach-case-study-mexico-dulce-wirelesstijuan english-.pdf. Accessed 1 Dec 2016.

16. Wireless Heart Health: Using $3 \mathrm{G}$ to Assist Underserved Patients with Cardiovascular Disease. Qualcomm wireless research. China. Available at: https://www.qualcomm.com/media/documents/files/ china-heart-health.pdf. Accessed 1 Dec 2016.

17. Sean Lunde. The mHealth case in India. Wipr council for industry research. Available at: http://www.wipro.com/documents/the-mHealthcase-in-India.pdf. Accessed 30 Nov 2016.

18. Using 3G Wireless Technology to Provide Timely Medicine to People with HIV/AIDS. Qualcomm wireless reach. Kenya. Available at https://www.qualcomm.com/news/onq/2014/12/09/ wireless-reach-using-3g-improve-delivery- medicine-people-hivaids-kenya. Accessed 3 Dec 2016.

19. Edward Boyer, Rich Fletcher, Richard Fay, David Smelson, Douglas Ziedonis, and Rosalind Picard. Preliminary Efforts Directed Toward the Detection of Craving of Illicit Substances: the iHeal Project. Journal of Medical Toxicology. 2012;8:5-9.

20. Albabtain AF, AlMulhim DA, Yunus F, Househ MS. The role of mobile health in the developing world: A review of current knowledge and future trends. JSHI. 2014;4(2):10-5.

21. Ryu S. Book Review: mHealth: New Horizons for Health through Mobile Technologies: Based on the Findings of the Second Global Survey on eHealth (Global Observatory for eHealth Series, Volume 3). Health Inform Res. 2012;18:231-3.

22. United Nations Foundation. "mHealth for Development: The Opportunity of Mobile Technology for Healthcare in the Developing World”. Washington, D.C. and Berkshire, UK: Vital Wave Consulting, 2009. Available at http://www.globalproblems-globalsolutions files.org/unf_website/assets/publications/technology /mhealth/mHealth_for_Development_full.pdf. Accessed 10 Dec 2016.

23. Inthiran A. A reflection of mHealth interventions in south east Asia. Article 2: volume 25. July 2015. Available at: http://www.iimahd.ernet.in/egov/ ifip/july2015/anushia-inthiran.html. Accessed 5 Dec 2016.

24. Global report on diabetes. 2016. World Health Organization. Geneva. Switzerland. Available at http://apps.who.int/iris/bitstream/10665/204871/1/9 789241565257_eng.pdf. Accessed 5 Dec 2016.

25. Anjana RM, Pradeepa R, Deepa M, Datta M, Sudha $\mathrm{V}$, Unnikrishnan $\mathrm{R}$ et al. ICMR-INDIAB Collaborative Study Group. Prevalence of diabetes and prediabetes (impaired fasting glucose and/or impaired glucose tolerance) in urban and rural India: phase I results of the Indian Council of Medical Research-INdiaDIABetes (ICMR-INDIAB) study. Diabetologia. 2011;54(12):3022-7.

26. Use of mobile technology to ensure immunisation coverage in Bangladesh. Press brief. International Centre for Diarrheal Disease Research, Bangladesh. Dhaka. Bangladesh. Available at http:// www.icddrb.org/dmdocuments/Use $\% 20$ of $\% 20$ mobil e\%20technology\%20to\%20ensure\%20immunisation $\% 20$ coverage $\% 20$ in $\% 20$ Bangladesh.pdf. Accessed 19 Nov 2016.

27. Fifty-eight world health assembly. Resolutions and decisions annex. 16-25 May 2005. World Health Organization. Geneva. Switzerland. Available at http://apps.who.int/gb/ebwha/pdf_files/WHA58-

REC1/english/A58_2005_REC1-en.pdf. Accessed 10 Dec 2016.

28. Highlights of Telecom Subscription Data as on 30th November, 2015. Telecom Regulatory Authority of India. New Delhi. Available at http:// 
trai.gov.in/WriteReadData/PressRealease/Document /PR-TSD-Nov-15.pdf. Accessed 10 Dec 2016.

29. Garai A, Ganesan R. Role of information and communication technologies in accelerating the adoption of healthy behaviors. $\mathrm{J}$ Fam Welf. 2010;56:109-18.

30. Annual report 2014-2015. Organization and Infrastructure. Ministry of Health and Family Welfare. Government of India. New Delhi. Available at http://mohfw.nic.in/WriteReadData/ 1892s/563256988745213546.pdf. Accessed 10 Dec 2016.

31. Mobile Health Services- Mobile Academy, Kilkari, M-Cessation and TB Missed Call initiative - to Strengthen Public Health Infrastructure. Press Information Bureau, Government of India, Ministry of Health and Family welfare. 2016. Available at: http://pib.nic.in/newsite/PrintRelease.aspx?relid=13 4503. Accessed 15 Dec 2016.

32. The commercialization of mHealth applications. Research to guidance Mobile health market report 2013-2017. 2013 March. Volume 3. Available at: http://www.research2guidance.com/shop/index.php/ downloadable/download/sample/sample_id/262/ webcite. Accessed 13 Dec 2016.

33. McCartney M. How do we know whether medical apps work? BMJ 2013;346:f1811.

34. Bennett GG, Glasgow RE. The delivery of public health interventions via the Internet: actualizing their potential. Annu Rev Public Health 2009;30:273-92.

35. Heffernan KJ, Chang S, Maclean ST, Callegari ET, Garland SM, Reavley NJ et al. Guidelines and Recommendations for Developing Interactive Health Apps for Complex Messaging in Health Promotion. JMIR MhealthUhealth. 2016 ;4(1):e14.

36. Barton AJ. The regulation of mobile health applications. BMC Med. 2012;10:46.

37. Census 2011. Office of registrar general and census commissioner, India Government of India. Ministry of home affairs. Available at: http://census india.gov.in/. Accessed 1 Jan 2017.

38. Darrell West. How mobile devices are transforming healthcare. Issues in technology innovation. Number 18. May 2012. Available at: https://www. brookings.edu/research/how-mobile-devices-aretransforming-healthcare/. Accessed 1 Jan 2017.

39. Brinkel J, Krämer A, Krumkamp R, May J, Fobil J. Mobile Phone-Based mHealth Approaches for Public Health Surveillance in Sub-Saharan Africa: A Systematic Review. Int J Environ Res Public Health. 2014;11(11):11559-82.
40. de Jongh T, Gurol-Urganci I, Vodopivec-Jamsek V, Car J, Atun R. Mobile phone messaging for facilitating self-management of long-term illnesses. Cochrane Database Syst Rev 2012;12:CD007459.

41. Gurol-Urganci I, de Jongh T, Vodopivec-Jamsek V, Car J, Atun R. Mobile phone messaging for communicating results of medical investigations. Cochrane Database Syst Rev 2012;6:CD007456.

42. Horvath T, Azman H, Kennedy GE, Rutherford GW. Mobile phone text messaging for promoting adherence to antiretroviral therapy in patients with HIV infection. Cochrane Database Syst Rev 2012;3:CD009756.

43. Smith C, Gold J, Ngo TD, Sumpter C, Free C. Mobile phone-based interventions for improving contraception use. Cochrane Database Syst Rev. 2015;6:CD011159.

44. Mission Indradhanush. National Health Portal of India. Available at: http://www.nhp.gov.in/ 1mission-indradhanush_pg. Accessed 12 Dec 2016.

45. Domek GJ, Contreras-Roldan IL, O'Leary ST, Bull S, Furniss A, Kempe A, et al. SMS text message reminders to improve infant vaccination coverage in Guatemala: A pilot randomized controlled trial. Vaccine. 2016;34:2437-43.

46. Haug S, Schaub MP, Venzin V, Meyer C, John U. Efficacy of a Text Message-Based Smoking Cessation Intervention for Young People: A Cluster Randomized Controlled Trial. J Med Internet Res. $2013 ; 15$.

47. Kerr DA, Pollard CM, Howat P, Delp EJ, Pickering $\mathrm{M}$, Kerr KR, et al. Connecting Health and Technology (CHAT): protocol of a randomized controlled trial to improve nutrition behaviours using mobile devices and tailored text messaging in young adults. BMC Public Health. 2012;12:477.

48. Wright JL, Sherriff JL, Dhaliwal SS, Mamo JCL. Tailored, iterative, printed dietary feedback is as effective as group education in improving dietary behaviours: results from a randomised control trial in middle-aged adults with cardiovascular risk factors. Int J Behav Nutr Phys Act. 2011;8:43.

49. WHO. New checklist published to help improve reporting of mHealth interventions. WHO. Available at http://www.who.int/reproductive health/topics/mhealth/mERA-checklist/en/. Accessed 15 Dec 2016.

Cite this article as: Ahamed F, Palepu S, Dubey M, Nongkynrih B. Scope of mobile health in Indian health care system - the way forward. Int J

Community Med Public Health 2017;4:875-81. 